\title{
Hubungan Footprint Test Terhadap Q Angle pada Remaja Usia 12-15 Tahun di SMP Muhammadiyah 2 Gamping Yogyakarta
}

\author{
Meiza Anniza(1) \\ Universitas 'Aisyiyah Yogyakarta \\ meizaanniza@unisayogya.ac.id \\ Rina Mayangsari(2) \\ Universitas 'Aisyiyah Yogyakarta \\ rinamayangsari28@gmail.com
}

DOI: 10.23917/varidika.v32i2.12147

Submission
Track:
Received:
15 Oktober 2020
Final Revision:
10 November 2020
Available online:
30 Desember 2020
Corresponding Author:
Meiza Anniza(1)
Rina Mayangsari(2)
meizaanniza@unisayogya.ac.id

\section{Submission}

ack

15 Oktober 2020

Final Revision:

Available online:

30 Desember 2020

Corresponding Author:

Meiza Anniza(1)

Rina Mayangsari(2)

meizaanniza@unisayogya.ac.id

\begin{abstract}
Footprint test is an examination used to determine the level of the Medial Longitudinal Arch (MLA) by observing the medial border of the foot. This measurement is performed to identify deformities in the foot, such as flatfoot. This condition can become a problem if the shape of the feet does not change towards normal with age. Since the foot is the most distal region, a change in this region will be followed by a change in a more proximal region. $Q$ angle is an important factor in assessing knee function. This research was conducted to determine the relationship between the footprint test and $q$ angle in adolescents aged 12-15 years at SMP Muhammadiyah 2 Gamping Yogyakarta. This type of research is an analytic survey using a cross sectional approach. The population in this study were students of SMP Muhammadiyah 2 Gamping who had met the inclusion criteria. The sampling technique in this study was purposive sampling with a total sample of 51 students. From the results of the bivariate analysis with the chi square correlation test, the value of $p=0.022$ ( $p<0.05)$ was obtained. This shows that Ho was rejected and Ha was accepted. Based on the objectives and research results, it can be concluded that there is a relationship between Footprint Test and $Q$ Angle in adolescents aged 12-15 years at SMP Muhammadiyah 2 Gamping Yogyakarta.

Keywords: footprint test, flatfoot, $Q$ angle, MLA.
\end{abstract}




\section{PENDAHULUAN}

Masa remaja merupakan suatu masa dimana anak mengalami transisi perkembangan dari masa kanak-kanak ke masa dewasa yang pada umumnya dimulai pada usia 12 atau 13 tahun dan berakhir pada umur akhir belasan tahun atau awal dua puluh tahunan. Masa dimana suatu individu memasuki tahap awal remaja pada umumnya dialami pada saat menduduki bangku Sekolah Menengah Pertama (SMP). Pada masa SMP siswa sudah mulai dikenalkan kegiatan ekstrakurikuler sesuai minat dan bakat yang dimiliki. Kegiatan ekstrakurikuler ini secara garis besar berhubungan dengan aktifitas fisik dimana aktifitas fisik tidak dapat terlepas dari peranan sistem muskuloskeletal.

Sistem muskuloskeletal terutama ekstremitas inferior yang menopang tubuh dalam melakukan aktifitas sehari-hari dapat mengalami gangguan, terutama jika terjadi perubahan biomekanik pada ankle joint yang salah satunya dapat disebabkan oleh bentuk kaki yang flatfoot (Febriana, 2016). Untuk mengidentifikasi kelainan bentuk kaki tersebut dapat dilakukan pengukuran berupa footprint test dengan memperhatikan batas medial kaki. Sidik telapak kaki dapat dilakukan dengan menggunakan media tinta. Pada footprint test, bentuk arcus kaki diketahui dengan cara membasahi kaki dengan cat, lalu menapakkannya pada selembar kertas sehingga pada kertas tadi akan tertinggal sidik telapak kaki (Anzai dkk, 2014). Kondisi ini secara tidak langsung dapat meningkatkan nilai derajat $q$ angle (Alkhouli, 2017).

$Q$ angle merupakan sudut yang terbentuk dari perpotongan dua garis imajiner yang diukur antara aksial tendon $m$. quadriceps femoris yang membagi dua ligamentum patella hingga tuberculum tibialis dan garis yang ditarik dari Spina Iliaca Anterior Superior (SIAS) hingga pertengahan patella pada saat lutut dalam keadaan ekstensi (Kurniawan, 2019). Q angle memiliki kaitan yang erat baik dengan regio yang lebih proksimal maupun dengan regio yang lebih distal. Otot perut berkaitan dengan $q$ angle dan ekstremitas inferior. Hal ini dapat diketahui dari adanya ketidakstabilan otot perut dapat mengakibatkan perubahan pada besarnya derajat $q$ angle (Christensen dan Okamatsu, 2019).

$Q$ angle merupakan suatu faktor penting yang perlu diperhatikan dalam menilai fungsi knee joint. Nilai derajad $q$ angle pada seseorang dikatakan normal jika berada dalam rentang 10-15 . Namun seseorang dikatakan berisiko cidera jika memiliki nilai derajad $q$ angle lebih dari $15^{\circ}$. Peningkatan nilai derajad $q$ angle yang berada diluar rentang normal ini merupakan suatu indikasi terjadinya malalignment pada ekstremitas inferior (Kurniawan, 2019) 
Perubahan alignment tubuh dapat menyebabkan gangguan pada tulang dan persendian. World Health Organization (WHO, 2016) menyatakan bahwa sekian ratus juta orang terganggu kehidupannya akibat gangguan persendian. Flatfoot merupakan salah satu gangguan pada tulang yang sering terjadi. Menurut Sahri (2017) angka prevalensi flatfoot dialami oleh sekitar $20 \%$ orang dewasa, bahkan menurut Inamdar dkk (2018) terdapat 34,2\% orang di India yang berusia 20- 60 tahun mengalami hal ini. Tidak hanya terjadi pada orang dewasa, kondisi ini pun dialami oleh anak anak dan remaja. Namun secara fisiologis seiring bertambahnya usia kondisi ini dapat teratasi (Demneh dkk, 2015).

Kondisi ini dapat berkembang menjadi lebih buruk jika tidak dicegah sedari dini. Berbagai masalah yang dapat terjadi yaitu gangguan pada jaringan lunak dan ekstremitas bawah (Lynn dkk, 2012; Mulligan dan Cook, 2013; Moon dkk, 2014; Mignona dkk, 2016; Okamura $\mathrm{dkk}, 2017$ ) seperti fasciitis plantaris (Adhikari dkk, 2014), osteoarthritis pada knee joint (Widodo, 2013), beberapa nyeri pada knee joint lainnya seperti kerusakan kartilago pada medial tibiofemoral dan lateral patellofemoral (Gross, 2012), nyeri punggung bawah (Galli dkk, 2013) serta deformitas ( Idris dkk, 2010; Mosca, 2010; Indardi, 2014).

Salah satu upaya yang merupakan pelayanan kesehatan untuk mencegah komplikasi lebih lanjut dari masalah diatas adalah dengan dilakukan pelayanan fisioterapi. Pelayanan fisioterapi yang dibutuhkan yaitu identifikasi sejak dini terhadap kondisi flatfoot. Skrining pada flatfoot dapat dilakukan dengan menggunakan footprint test metode Chippaux Smirax-Index (CSI) (Banwell dkk, 2018). Dan juga dengan adanya identifikasi dini diharapkan kondisi ini dapat segera diberikan intervensi yang sesuai.

Mengingat tingginya angka kejadian flatfoot, sedangkan informasi mengenai hubungannya terhadap $q$ angle pada semua kelompok usia di Indonesia masih sangat terbatas. Dengan demikian penulis tertarik untuk melakukan penelitian mengenai keterkaitan antara footprint test dengan q angle pada remaja usia 12-15 tahun di SMP Muhammadiyah 2 Gamping Yogyakarta.

\section{METODE PENELITIAN}

Penelitian ini merupakan penelitian survey analitik dengan pendekatan cross sectional . Metode ini digunakan dengan tujuan agar diperoleh data yang lengkap dalam waktu yang relatif singkat dimana pengumpulan data dilakukan dalam waktu tiga hari di SMP Muhammadiyah 2 Gamping Yogyakarta pada tanggal 3 sampai 5 Desember 2019. 
Populasi dalam penelitian ini meliputi siswa dari kelas VII A, VII B, dan VII C di SMP Muhammadiyah 2 Gamping Yogyakarta dengan kondisi flatfoot sebanyak 99 siswa. Teknik pengambilan sampel yang digunakan yaitu purposive sampling dengan jumlah sampel sebanyak 51 siswa yang telah memenuhi kriteria inklusi sebagai berikut: 1) Siswa SMP Muhammadiyah 2 Gamping Yogyakarta baik laki-laki maupun perempuan yang berusia 12-15 tahun; 2) Siswa yang mengalami flatfoot dalam kategori derajad 1 diketahui dari hasil footprint test; 3 ) Subjek penelitian dalam kondisi sehat dan tidak pernah mengalami gangguan pada ekstremitas bawah seperti fraktur, amputasi, atau sedang menggunakan alat bantu jalan; 4) Subjek penelitian kooperatif dan bersedia mengikuti program penelitian sampai akhir.

Tujuan dari penelitian ini adalah untuk mengetahui adanya hubungan footprint test terhadap $q$ angle pada remaja usia 12-15 tahun di SMP Muhammadiyah 2 Gamping Yogyakarta. Variabel yang dipilih dalam penelitian ini adalah : 1) Variabel independen ( $\mathrm{x})=$ footprint test. Footprint test merupakan suatu pengukuran yang digunakan untuk mengidentifikasi kelainan pada bentuk kaki (arcus pedis). Setelah dilakukan footprint test maka hasilnya diukur dengan metode chippaux - smirak index (CSI).

CSI merupakan suatu metode penilaian pada hasil footprint test dengan melihat area midfoot yang ditapakkan di atas permukaan halus. Metode ini direkomendasikan untuk menunjukkan interpretasi dari footprint test pada arcus pedis. Arcus diukur dengan membagi nilai zona sempit midfoot $(\mathrm{h})$ dengan nilai garis paralel pada zona yang lebih luas dari kaki depan (f) dan mengalikannya dengan 100 persen (h/f x 100\%). Maka akan didapatkan hasil derajat flatfoot (Banwell dkk, 2018).

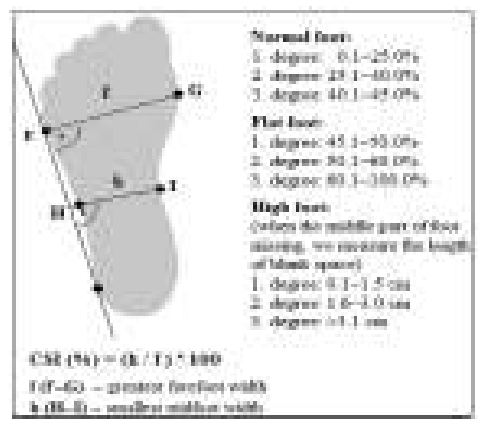

Gambar 1. Metode Chippaux-Smirak Index (CSI)

(Banwell dkk, 2018) 
Dari hasil footprint test dengan metode CSI maka bentuk kaki seseorang dapat dikategorikan kedalam 2 bentuk, yaitu normal jika nilai hasil footprint test memiliki rentang antara $0,1-25,0 \%$ sampai $40,1-45,0 \%$ dan flatfoot jika memiliki rentang antara 45,1-50\% sampai 60,1-100\% sehingga skala data dari variabel ini merupakan skala data nominal, 2) Variabel dependen $(\mathrm{y})=q$ angle. $Q$ angle merupakan suatu sudut yang terbentuk dari perpotongan dua garis imajiner. $Q$ angle dikategorikan kedalam 2 kategori, yaitu normal jika derajadnya bernilai $10-15^{0}$ dan berisiko cidera jika derajadnya bernilai $>15^{0}$ sehingga skala data dari variabel ini merupakan skala data nominal.

Alat yang digunakan dalam penelitian ini adalah : a) Lembar informed consent; b) Alat tulis berupa pena, penggaris dan spidol untuk menandai posisi; c) Buku catatan; d) Midline; e) Goniometer; f) Kamera; g) Kertas dan baskom/ ember yang berisi air untuk media pemeriksaan footprint test; h) Tinta yang mudah hilang dan aman untuk kulit.

Cara melakukan Footprint Test adalah sebagai berikut:

1. Responden diminta untuk mencuci dan membersihkan kakinya terlebih dahulu sampai bersih dan kering.

2. Responden diminta memasukkan kakinya kedalam nampan yang berisi tinta, dilakukan pada posisi berdiri.

3. Kaki yang telah diinjakkan pada tinta, responden diminta untuk menapakkannya ke kertas yang telah disesuaikan oleh fisioterapis.

4. Responden memindahkan kakinya kedalam ember yang berisi air untuk membersihkan telapak kakinya dari tinta dan membersihkan ulang dengan kain lap sampai bersih dan kering.

5. Responden melakukan pengulangan pada kedua kaki secara bergantian.

6. Kertas yang telah berisi cetakan kaki responden, didiamkan beberapa menit agar tintanya kering.

7. Cetakan kaki tersebut diukur oleh fisioterapis dengan menggunakan metode chippauxsmirak index.

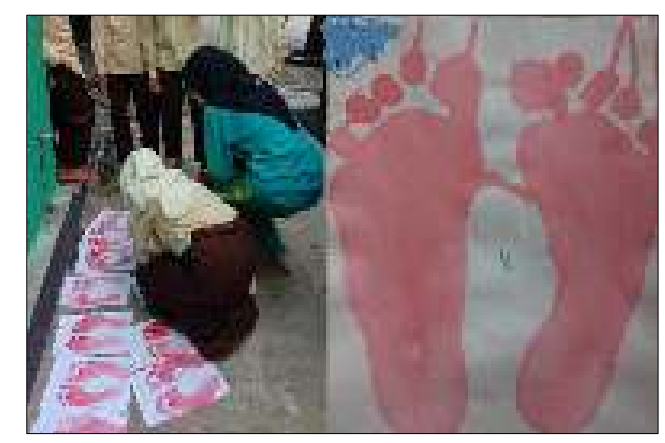


Gambar 2. Pelaksanaan Footprint Test

(Dokumentasi pribadi, 2019)

Cara melakukan pengukuran derajat $q$ angle adalah sebagai berikut:

1. Pengukuran dilakukan dengan ditemani 1 orang asisten penelitian. Responden diminta untuk memakai celana pendek atau mengangkat celananya sebatas atas lutut atapun celana tipis yang tidak menghalangi palpasi struktur-struktur ekstremitas inferior

2. Responden diminta untuk berdiri dengan kaki terbuka selebar bahu dan posisi seimbang tidak bertumpu pada salah satu kaki.

3. Mengukur $q$ angle responden dengan menggunakan goniometer standar. Mencari patokan garis yang ditarik dari SIAS ke pusat dan garis yang memanjang dari tuberositas tibiae ke pusat os.patella. Pengukuran dilakukan pada kaki kiri terlebih dahulu kemudian kaki kanan.

4. Mencatat hasil pengukuran.

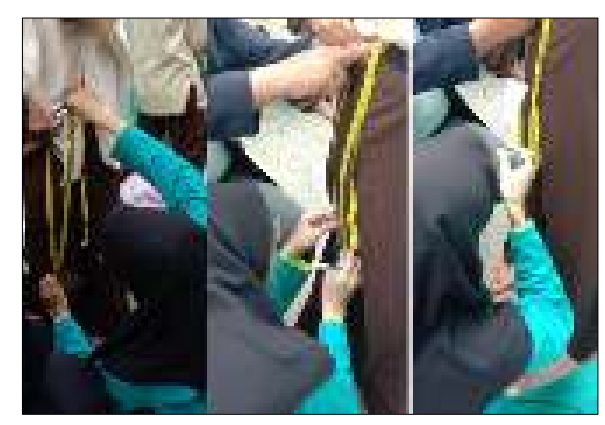

Gambar 3. Pengukuran $Q$ Angle

(Dokumentasi pribadi, 2019)

Analisis data dilakukan untuk menjawab hipotesis penelitian. Untuk alasan tersebut digunakan uji statistik yang cocok dengan variabel penelitian. Analisa data dibagi menjadi 2 
bagian yaitu analisa univariate dan bivariate. Namun sebelum melakukan analisa bivariate dilakukan uji normalitas terlebih dahulu.

Uji normalitas adalah bentuk pengujian tentang kenormalan distribusi data. Uji normalitas data yang digunakan adalah uji Kolmogorov-Smirnov. Dalam uji normalitas ini digunakan $\alpha$ sebagai batas kemaknaan dengan nilai 0,05 . Untuk dilihat posisi probabilitasnya (p). Jika nilai $\mathrm{p}>0,05$ maka menunjukkan bahwa data berdistribusi normal. Jika nilai $\mathrm{p}<0,05$ maka menunjukkan bahwa data berdistribusi tidak normal. Setelah uji normalitas data maka dilakukan analisa univariate dan bivariate.

Uji analisa univariate merupakan analisis yang menjelaskan atau mendeskripsikan karakteristik setiap variabel penelitian. Bentuk analisis univariate tergantung dari datanya, pada umumnya dalam penelitian ini hanya menghasilkan distribusi frekuensi responden berdasarkan: umur, jenis kelamin, serta pengukuran derajat flatfoot. Sedangkan uji analisa bivariate yang digunakan adalah uji non parametrik chi square.

\section{HASIL DAN PEMBAHASAN}

\section{Analisa Univariate}

Karakteristik responden dalam penelitian ini adalah siswa-siswi Sekolah Menengah Pertama yang telah memenuhi kriteria inklusi. Pada penelitian ini semua responden yang berjumlah 51 siswa bersedia untuk diambil data dirinya dan dilakukan pengukuran.

Tabel 1. Karakteristik Responden

\begin{tabular}{|c|c|c|c|}
\hline \multicolumn{2}{|c|}{ Karakteristik } & $\mathrm{n}$ & Mean \pm SD \\
\hline Umur & $12-15$ & $\begin{array}{l}51 \\
51\end{array}$ & $\begin{array}{l}12,94 \pm \\
152+050\end{array}$ \\
\hline $\mathrm{OA}$ & 0 & 51 & $10.52 \pm 0.85$ \\
\hline $\mathrm{FF}$ & $\begin{array}{c}4 \\
-1\end{array}$ & 51 & $1.00 \pm 0.00$ \\
\hline
\end{tabular}

Keterangan :

SD : Standar Deviasi

n : Jumlah Sampel

LK : Laki-Laki

PR : Perempuan 
QA : derajad q angle

FF : flatfoot

Berdasarkan tabel 1 dapat diketahui karakteristik responden dalam penelitian ini berupa umur, jenis kelamin dan nilai derajad $q$ angle.

Tabel 2. Distribusi Footprint Test Berdasarkan Umur

\begin{tabular}{ccc}
\hline Umur & $\mathrm{n}$ & $\%$ \\
\hline 12 & 22 & 43,1 \\
13 & 15 & 29,4 \\
14 & 9 & 17.6 \\
15 & 5 & 9.8 \\
\hline Jumlah & 51 & 100 \\
\hline Sumber : Olah data (2019)
\end{tabular}

Keterangan :

n : Jumlah Sampel

$\%$ : Persentase

Berdasarkan tabel 2 dapat diketahui bahwa responden terbanyak terdapat pada siswa dengan kelompok umur 12 tahun $(43,1 \%)$ dan responden paling sedikit terdapat pada siswa dengan kelompok umur 15 tahun $(9,8 \%)$.

Tabel 3. Distribusi Footprint Test Berdasarkan Jenis Kelamin

\begin{tabular}{ccc}
\hline Jenis & $\mathrm{n}$ & $\%$ \\
\hline LK & 24 & 47,1 \\
PR & 27 & 52,9 \\
\hline Jumlah & 51 & 100 \\
\hline \multicolumn{3}{l}{ Sumber : Olah data $(2019)$}
\end{tabular}

Keterangan :

PR: Perempuan

LK: Laki-laki

n : Jumlah Sampel

$\%$ : Persentase

Berdasarkan tabel 3 dapat diketahui bahwa responden terbanyak terdapat pada siswa dengan jenis kelamin perempuan (52,9\%) dan responden paling sedikit terdapat pada siswa dengan jenis kelamin laki-laki (47,1\%). 
Tabel 4. Distribusi Footprint Test Berdasarkan $Q$ Angle

\begin{tabular}{ccc}
\hline $\mathrm{QA}\left({ }^{0}\right)$ & $\mathrm{n}$ & $\%$ \\
\hline 9 & 6 & 11.8 \\
10 & 18 & 35,3 \\
11 & 21 & 41.2 \\
12 & 6 & 11.8 \\
\hline Jumlah & 51 & 100 \\
\hline \multicolumn{2}{l}{ Sumber : Olah data (2019) }
\end{tabular}

Keterangan :

QA: derajad $q$ angle

n : Jumlah Sampel

$\%$ : Persentase

Berdasarkan tabel 4 dapat diketahui bahwa responden terbanyak terdapat pada siswa dengan kelompok nilai $q$ angle sebesar $11^{0}(41,2 \%)$ dan responden paling sedikit terdapat pada siswa dengan kelompok nilai $q$ angle sebesar $6^{0}(11,8 \%)$.

\section{Uji Normalitas}

Pada penelitian ini uji normalitas yang digunakan adalah Kolmogorov Smirnov karena jumlah sampel lebih dari 40 orang.

Tabel 5. Hasil Uji Normalitas

\begin{tabular}{lc}
\hline Variabel & Nilai p Kolmogorov Smirnov \\
\hline FF & 0,006 \\
QA & \\
Sumber : Olah data (2019)
\end{tabular}

Keterangan :

FF : flatfoot

QA : derajad q angle

Berdasarkan tabel 5 dapat diketahui bahwa hasil uji normalitas pengukuran flatfoot dan $q$ angel yaitu $\mathrm{p}=0,006(\mathrm{p}<0,05)$ maka data berdistribusi tidak normal. 


\section{Analisa Bivariate}

Uji korelasi yang digunakan untuk mengetahui adanya hubungan footprint test terhadap $q$ angle pada remaja usia 12-15 tahun di SMP Muhammadiyah 2 Gamping Yogyakarta adalah uji non parametrik Chi Square.

Tabel 6. Hasil Uji Chi Square

\begin{tabular}{cc}
\hline Variabel & Asymp. Sig \\
\hline FF & 0,022 \\
QA & \\
\hline Sum : Olah data $(2019))$
\end{tabular}

Sumber : Olah data (2019)

Keterangan :

FF : flatfoot

QA : derajad q angle

Berdasarkan tabel 6 hasil uji chi square dari pengukuran flatfoot dan $q$ angel yaitu $\mathrm{p}=$ $0,022(\mathrm{p}<0,05)$. Sesuai dengan ketentuan jika $\mathrm{p}<0,05$ maka Ho ditolak dan Ha diterima. Dari hasil uji chi square diatas dapat ditarik kesimpulan bahwa data menunjukkan "Adanya Hubungan Footprint Test Terhadap $Q$ Angle pada Remaja Usia 12-15 Tahun di SMP Muhammadiyah 2 Gamping, Yogyakarta".

Pada penelitian yang dilakukan oleh peneliti, berdasarkan hasil uji hipotesis dan hasil penelitian menunjukkan bahwa semakin tinggi derajad pes planus maka semakin tinggi pula nilai derajad $q$ angle. Hal ini sesuai dengan teori biomekanika kaki dimana kondisi pronasi yang berlebihan menyebabkan tekanan internal rotasi pada kaki sehingga terjadi masalah angulasi pada tendon patella dan menekan sisi lateral facet patella secara berlebihan, maka dari itu kondisi kaki yang berlebihan dapat meningkatkan bentuk valgus pada knee joint yang diikuti peningkatan pada nilai q angle (Letafatkar, 2013; Lee dan Chon, 2018; Kurniawan, 2019). 
Peningkatan pada nilai derajad $q$ angle yang diikuti oleh peningkatan internal rotasi pada hip joint (Letafatkar,2013) terjadi dikarenakan adanya kelemahan pada otot abductor hip dan ketegangan pada otot adductor hip. Ketidakseimbangan kerja pada otot agonis dan antagonis pada hip joint dapat menyebabkan perubahan pada Center of Gravity (COG) yang cenderung ke arah posterior sehingga alignment tubuh mengalami perubahan (Febriana, 2016), perubahan ini pun ditemukan pada besarnya derajat $q$ angle yang mengalami peningkatan (Pritti G, 2019).

Berdasarkan antropometri tubuh, banyak komponen sepanjang hip- knee-ankle joint yang mengalami perubahan. Komponen tersebut meliputi tibiofemoral angle, femoral anteversion, genu recurvatum, tibial torsion, pelvic width, arm span, condylar distance, dan (WHR) (Kurniawan, 2019).

\section{KESIMPULAN}

Hasil penelitian dan pembahasan menunjukkan adanya hubungan antara footprint test dengan $q$ angle pada remaja usia 12-15 tahun di SMP Muhammadiyah 2 Gamping Yogyakarta. Hal ini diketahui dari hasil uji data bivariate menggunakan Chi Square dengan $p=0,022(p<$ 0,05), hal ini menunjukkan bahwa Ho ditolak dan Ha diterima. Dari hasil tersebut maka dapat ditarik kesimpulan bahwa adanya Hubungan Footprint Test Terhadap Q Angle pada Remaja Usia 12-15 tahun di SMP Muhammadiyah 2 Gamping Yogyakarta.

\section{REFERENCES}

Adhikari, U, Arulsingh, W, Pai, G, \& Raj, J. O. (2014). Normative Values of Navicular Drop Test and the Effect of Demographic parameters- A Cross Sectional Study. Annals of Biological Research, Vol. 5. No. 7. 40-48.

Alkhouli, M. N., Ghait, A, S., Abogazya, A. A. (2017). Relationship Between Flatfoot and Q Angle in Male Secondary School Student. International Journal of Physiotherapy and Research, Vol 5(6):2477-81. ISSN 2321-1822.

Anzai, E., Nakajima, K., Iwakami, Y., Sato, M., Ifukube, T., Yamashita, K., \& Ohta Y. (2014). Effects of Foot Arch Structure on Postural Stability. Clin Res Foot Ankle, Vol. 2. No: 2. Maret 2014:1-5.

Banwell, H.A., Paris,M.E., Mackintosh, S, dan Williams, C.M. (2018). Pediatric Flexible Flat Foot: How Are We Measuring It and Are We Getting It Right? A Systematic Review. Journal of Foot and Ankle Research, 11:21.

Christensen, B dan Okamatsu, H. (2019). The Relationship Between Abdominal Muscular Strength and Quadriceps Angle in Subjects with Patellofemoral Pain.

Demneh, E, S., Melvin J,M., Azadinia, F., Shamsi, F., Jafarpishe, M. (2015). Flatfoot in School-Age Children: Prevalence and Associated Factor. Foot Ankle Specialist Journal, Vol. 8. No. 3. 186-193. 
Febriana, L. (2016). Hubungan Berat Badan Berlebih Dengan Perubahan Medial Longitudinal Arch dan Foot Alignment di Kecamatan Kertasura. Skripsi. Universias Muhammadiyah Surakarta.

Galli, M, Rigoldi, C., Costici, P., Albertini, G.. (2013). The Effects of Low Arched Feet on Foot Rotation During Gaitin Children with Down Syndrome. Journal of Intellectual Disability Research. doi: 10.1111/jir.12087.

Gross, K. D, Felson, D, T., Niu, J., Hunter, D, J., Guermazi, A., Roemer, F, W., Dufour, A, $\underline{B}$., Gensure, R, H., Hannan, M, T. (2012). Flat Feet Are Associated With Knee Pain and Cartilage Damage in Older Adults. doi: 10.1002/acr.20431.

Idris, F. H. (2010). Filogeni dan Ontogeni Lengkung Kaki Manusia. Majalah Kedokteran Indonesia, Vol. 60. No. 2. 74-80.

Inamdar, P., Fatnani, D., Rajiwate, F., Shaikh, B., Despandhe, B., Shaikh, S., Ranka, B., Dhansay, S. (2018). Prevalence of Flat Foot and High Arched Foot in Normal Working Individuals Using Footprint Method. International Journal of Physiotherapy and Research, Vol. 6. No. 3. 2754-58. ISSN 2321-1822. doi: https://dx.doi.org/10.16965/ijpr.2018.135.

Indardi, N. (2014). Latihan Fleksi Telapak Kaki dengan Kinesio Taping pada Fleksibel Flat Foot. Jurnal Media Ilmu Keolahragaan Indonesia, Vol. 4. No. 2. 68- 71. ISSN: 2088-6802.

Kurniawan, H. M. (2019). Hubungan antara Body Mass Index (BMI) dengan Q Angle. Jurnal Kedokteran Diponegoro, Vol. 8. No. 1.

Lee, K. H dan Chon, S. C. (2018). The Relationship Between the Range of Hip Rotation and the Quadriceps Angle in Subjects With and Without Flat Foot. Physical Therapy Korea 2018, Vol. 25. No. 4. 19-26.

Letafatkar, A., Zandi, S., Khodayi, M., dan Vashmesara, B. (2013). Flat Foot Deformity, Q Angle and Knee Pain are Interrelated in Wrestlers. Journal of Novel Physiotherapies, Vol. 3. Issue. 2. doi: 10.4172/2165-7025.1000138. ISSN: 2165-7025.

Lynn, S. K, Padilla, R, A., dan Tsang, K, K, W. (2012). Differences in Static- and Dynamic Balance Task Performance After 4 Weeks of Intrinsic-Foot - Muscle Training: The Short-Foot Exercise Versus The Towel- Curl Exercise. Journal of Sport Rehabilitation, 327-333.

Mignona, C. A., Lawren, A, W., Matthew, C, H. (2016). The Effects of Short Foot Exercises on Postural Control: A Critically Appraised Topic. International Journal of Athletic Therapy \& Training, 8-12.

Moon. D. C., Kim, K, dan Lee, S. (2014). Immediate Effect of Short- Foot Exercise on Dynamic Balance of Subjects with Excessively Pronated Feet. Journal Physical Therapy of Science, Vol. 26. No. 21. 117-119.

Mosca, V. S. (2010). Flexible Flatfoot in Children and Adolescents. Journal of Children's Orthopaedics, 107-121. doi: 10.1007/s11832-010-0239-9.

Mulligan, E. P. dan Cook, P. G. (2013). Effect of Plantar Intrinsic Muscle Training on Medial Longitudinal Arch Morphology and Dynamic Function. Manual Therapy Journal, 425-430.

Pritti G, L. (2019). Correlation of Quadriceps Angle With Foot Position In Knee Osteoarthritis. International Journal of Basic and Applied Research, Vol. 9. No. 3. ISSN 2249-3352 (P) 2278-0505 (E).

Sahri., Sugiarto., dan Vidiantoro, V. (2017). Hubungan Lengkung Telapak Kaki dengan Kelincahan. Semarang. Universitas Negeri Semarang. Jendela Olahraga. ISSN:2572 - 9580, Vol. 2. No. 1. 120-128. 
JURNAL VARIDIKA

Vol. 32, No. 2, 2020, pp/ 103-115 p-ISSN 0852-0976 | e-ISSN 2460-3953 Website: http://journals.ums.ac.id/index.php/varidika

World Health Organization (WHO). 2016. Musculoskeletal Fact Sheets. Diunduh dari http://www.who.int/mediacentre/factsheets/fs307/en/ 16 Oktober 2019.

Widodo, A dan H, R. N. F. (2013). Hubungan Antara Pes Planus dengan Osteoarthritis Knee. Jurnal Kesehatan, Vol. 6. No. 2. 209-216. ISSN 1979- 7621. 